\title{
OS DESAFIOS DO CONSÓRCIO INTERMUNICIPAL DE RESÍDUOS SÓLIDOS DO VALE DO AÇU, RIO GRANDE DO NORTE
}

\author{
THE CHALENGES OF THE SOLID WASTE INTER-MUNICIPAL CONSORTIUM OF THE AÇU VALLEY, STATE OF RIO \\ GRANDE DO NORTE
}

\section{RESUMO}

Os resíduos sólidos constituem um dos graves problemas urbanos no mundo atual para o qual se busca soluções urgentes. No Brasil, o enfrentamento oficial dessa questão só ocorreu recentemente quando o governo federal sancionou a Lei 12.305/2010, que dispõe sobre a Política Nacional de Resíduos Sólidos. Apesar da lei, a maioria dos municípios brasileiros não tem avançado neste tema. A falta de gestão e de destinação adequada para os resíduos sólidos urbanos são apontadas como desafios a serem superados. Para tanto, uma das alternativas encontrada tem sido a criação de consórcios intermunicipais. No estado do Rio Grande do Norte, o governo estadual instituiu em 2010 o Plano Estadual de Gestão Integrada de Resíduos Sólidos e o ordenamento geográfico dos 167 municípios que passaram a integrar 07 Consórcios Regionais de Saneamento Básico. O Consórcio Regional de Saneamento Básico do Vale do Açu, desde a sua criação não conseguiu sair do papel. A pesquisa investigou os obstáculos que dificultam a sua operacionalização e constatou que a situação econômica dos municípios, a rotatividade dos prefeitos, a distância das cidades para a sede do aterro sanitário e a falta de envolvimento da população são obstáculos à sua operacionalização.

Palavras-chave: Resíduos sólidos. Vale do Açu. Consórcio intermunicipal. Política Nacional de Resíduos sólidos, Nordeste do Brasil.

\section{ABSTRACT}

Solid waste is one of the serious urban problems in contemporary world, for which urgent solutions are sought. In Brazil, the official confrontation of this issue only occurred recently when the federal government sanctioned Law 12.305/2010, which deals with the National Policy on Solid Waste. Despite the law, most Brazilian municipalities have not made progress on this issue. The lack of management and adequate disposal for solid urban waste are pointed out as challenges yet to overcome. Therefore, one of the alternatives found has been the creation of intermunicipal consortia. In the state of Rio Grande do Norte, the state government instituted in 2010 the State Plan for Integrated Management of Solid Waste and the geographical ordering of the 167 municipalities that joined 07 Regional Consortia of Basic Sanitation. The Regional Basic Sanitation Consortium of the Açu Valley, since its creation has not been able to get off the ground. The research investigated the obstacles that hinder its operation and found that the poor economic situation of the municipalities, the turnover of mayors, the distance from the cities to the landfill site and the lack of involvement of the population are obstacles to its operation.

Keywords: Solid waste. Açu Valley. Inter-municipal consortium. National solid waste policy. Northeast of Brazil.
Raimundo Inácio da Silva Filho ${ }^{a}$

\section{Antonio Carlos de Barros} Corrêa ${ }^{\text {b }}$

a Universidade do Estado do Rio Grande do Norte (UERN), Mossoró, RN, Brasil

${ }^{\text {b }}$ Universidade Federal de Pernambuco (UFPE), Recife, PE, Brasil

DOI: 10.12957/geouerj.2020.51274

Correpondência: antonio.correa@ufpe.br

Recebido em: 27 mai. 2020

Aceito em: 28 set. 2020 


\section{INTRODUÇÃO}

Os resíduos sólidos têm se constituído como um dos graves problemas da atualidade em todo o mundo, a ponto de ser tema de discussão de vários estudiosos, de diferentes áreas do conhecimento (KAUTSKY, 1998; CAPRA, 2002; BAUMAN, 2008; 2009; NUNES; BASTOS, 2018). Na Europa a destinação final dos resíduos sólidos tem apresentado êxito: "En general, en la UE cada vez se reciclan más residuos y cada vez se destinan menos a los vertederos. En el caso de los residuos urbanos, el porcentaje de residuos reciclados o compostados en la Europa de los Veintisiete aumentó del 31 \% en 2004 al 41 \% en 2012" (AGÊNCIA EUROPEIA DE MEIO AMBIENTE, 2014, p. 6).

No Brasil a preocupação com os resíduos sólidos foi tardia. Muito demoradamente o país se deu conta da necessidade de enfrentamento do problema, embora já existissem experiências e estudos sobre a coleta, o tratamento e a reciclagem eficientes, como mostram alguns estudos (MANDELLI; LIMA; OJIMA, 1991; EIGENHEER, 1998; CALDERONI, 2003; PHILIPPI JR., 2005; PEREIRA NETO, 2007).

Somente em 2010 o governo federal sancionou a Lei 12.305, de 2 de agosto de 2010, que dispõe sobre a Política Nacional de Resíduos Sólidos (PNRS) e o Decreto 7.404/2010, de 23 de dezembro de 2010, que estabelece normas para a execução da PNRS. A PNRS emergiu como sendo um marco nas metas de eliminação e recuperação dos lixões em todo o país. Entretanto, apesar desse avanço o gerenciamento dos resíduos sólidos, na maioria dos municípios brasileiros, não tem se revelado eficiente, conforme insistem ABRELPE (2015), Brasil (2017), SELUR (2017) e CEMPRE (2018a; 2018b; 2019). Por todas essas questões, Schneider et al (2013, p. 14) admitem ser "natural que as soluções para a destinação final dos resíduos sólidos urbanos sejam intermunicipais".

Buscando resolver o problema causado pelos RSUs no Rio Grande do Norte, o governo estadual instituiu, em fins de 2010, o Protocolo de Intenções que trata do ordenamento territorial dos Consórcios Regionais de Saneamento Básico do Seridó, do Alto Oeste, do Mato Grande, do Agreste e do Vale do Açu, e do Plano Estadual de Gestão Integrada de Resíduos Sólidos do Rio Grande do Norte - PEGIRS/RN, em 2012. De fato, criaram-se expectativas nos prefeitos dos municípios dessas microrregiões geográficas do estado.

Na microrregião geográfica do Vale do Açu/RN, recorte espacial do presente estudo, a situação não foi diferente nos nove municípios que integram o Consórcio Regional de Saneamento Básico do Vale do Açu, uma vez que nessa microrregião os resíduos sólidos gerados são dispostos em lixões assim como ocorre nos demais quinze municípios que integram o referido consórcio (Figura 1). Face ao exposto, o presente trabalho busca identificar os motivos que dificultam a operacionalização do Consórcio Regional de Saneamento Básico do Vale do Açu. 


\section{MATERIAIS E MÉTODOS}

O recorte espacial deste estudo compreende os nove municípios que integram a microrregião do Vale do Açu, os quais participam da formação do Consórcio Regional de Saneamento Básico do Vale do Açu, a saber: Alto do Rodrigues, Assú, Carnaubais, Ipanguaçu, Itajá, Jucurutu, Pendências, Porto do Mangue e São Rafael. A amostra representa $37,5 \%$ dos municípios, os quais possuem cerca de $60 \%$ da população total dos que passaram a integrar o Consórcio Regional de Saneamento Básico do Vale do Açu, conforme revela a Figura 1.

Figura 1. Municípios integrantes da microrregião do Vale do Açu e do Consórcio Regional de Saneamento Básico. Fonte: Silva Filho (2019, p. 41), adaptado do Rio Grande do Norte (2016a, p. 10; 2016b, p. 48).

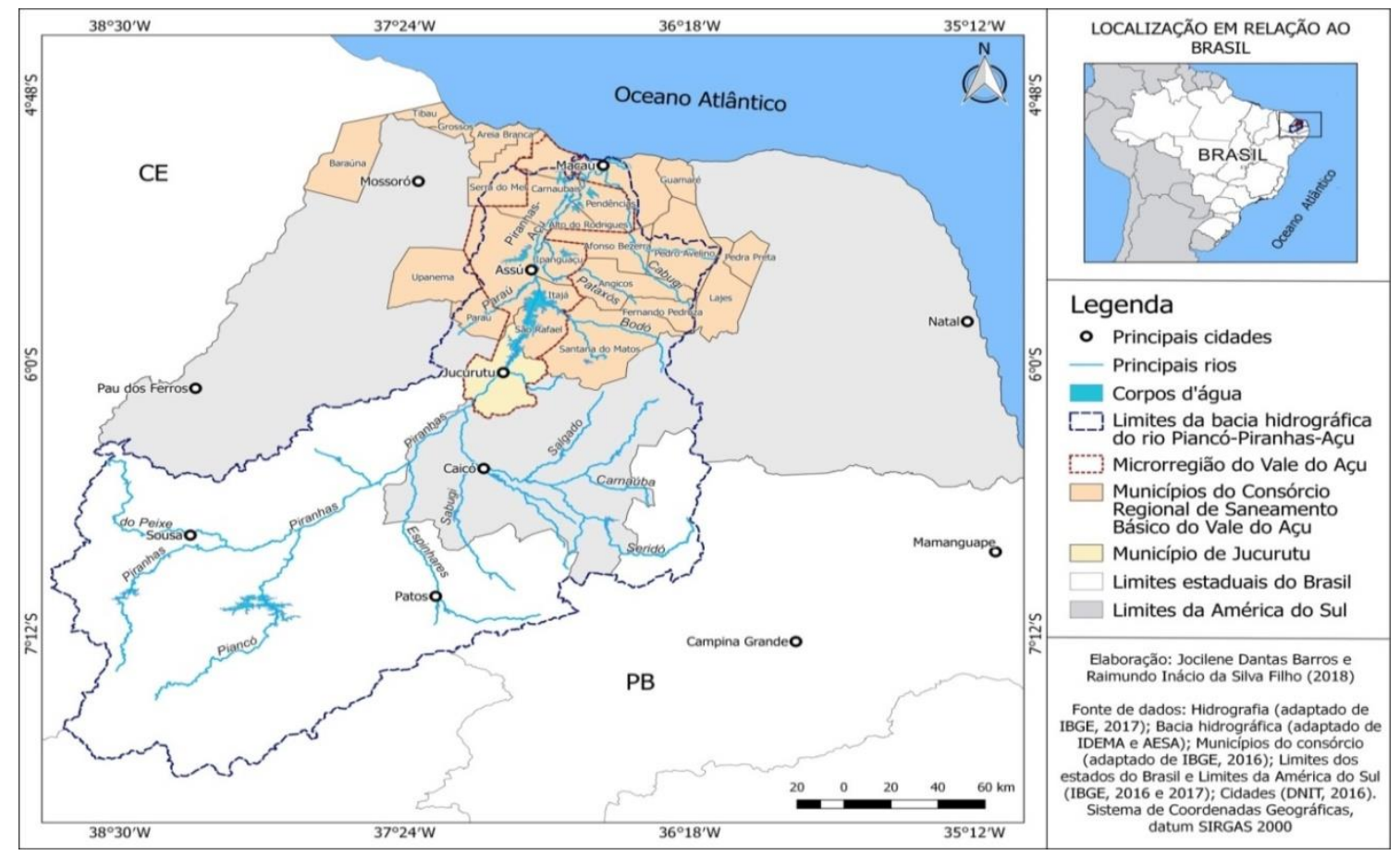

A área do Consórcio Regional de Saneamento Básico do Vale do Açu compreende um agrupamento regional - delimitado, planejado e denominado pelo governo do Rio Grande do Norte - composto por 24 municípios no qual residem 232.444 habitantes que geram mensalmente 3.485 toneladas de resíduos sólidos (RIO GRANDE DO NORTE, 2012, p. 87), as quais são jogadas diariamente em lixões.

É importante frisar que a escolha pelos nove municípios da microrregião do Vale do Açu não seguiu apenas o critério amostral; deu-se, acima de tudo, pelo fato de que esta microrregião possui com uma identidade sociocultural e está inserida na área da bacia hidrográfica do Rio Piranhas-Açu, a qual já sofre com o despejo irregular de lixo ao longo do leito do seu canal principal e de alguns tributários.

Na revisão bibliográfica, recorremos aos mais recentes estudos sobre o tema. Quanto aos dados da pesquisa, os mesmos foram obtidos em fontes primárias, mediante entrevistas e aplicação de questionários 
com os ex-prefeitos e os prefeitos em exercício dos municípios do Vale do Açu; com a Secretaria do Meio Ambiente e dos Recursos Hídricos (SEMARH); com a Federação dos Municípios do Estado do Rio Grande do Norte (FEMURN) e com o presidente do Consórcio Regional de Saneamento Básico do Vale do Açu. O estudo teve a participação de vinte e um gestores municipais e a consulta a fontes secundárias, tais como os dados obtidos junto ao Rio Grande do Norte (2010; 2012; 2016a; 2016b; 2016c; 2016d; 2016d; 2016e), à Associação Brasileira de Empresa de Limpeza Pública e Resíduos Especiais - ABRELPE (2015) e ao Sindicato das Empresas de Limpeza Urbana no Estado de São Paulo - SELUR (2017).

Para elucidar as questões acima, o presente trabalho, a partir destas considerações iniciais, propõe uma discussão sobre o lixo e os resíduos sólidos, elencando a gênese e os diferentes conceitos, a classificação e os riscos ao meio ambiente. Destacamos, ainda, a disposição dos resíduos sólidos e os desafios da coleta seletiva no Brasil, no Nordeste e no Rio Grande do Norte. Em seguida, tratamos sobre a problemática do lixo e dos resíduos sólidos, os riscos da poluição do meio ambiente, as práticas de disposição ambientalmente inadequada dos resíduos sólidos n Brasil, no Rio Grande do Norte e no Vale do Açu. Na sequência, mostramos a origem e os avanços da discussão relacionada aos consórcios públicos no Brasil e as perspectivas dos consórcios regionais de saneamento básico no RN, o Consórcio Regional de Saneamento Básico do Vale do Açu, as características gerais dos municípios e dos resíduos sólidos da Região de Assú. Consórcio. Os resultados da pesquisa são elencados mostrando os obstáculos à operacionalização do Consórcio Regional de Saneamento Básico do Vale do Açu. Nele são expostas as opiniões dos ex-prefeitos, prefeitos em exercício dos mandatos, secretários municipais e gestores da FEMURN, da SEMARH e do referido consórcio. Por fim são tecidas considerações finais sobre o tema abordado e apresentadas sugestões de superação aos obstáculos que limitam a operacionalização do Consórcio Regional de Saneamento Básico do Vale do Açu a partir das avaliações feitas pelos gestores (ex-prefeitos, prefeitos em exercício e secretários).

A problemática do lixo e dos resíduos sólidos: algumas definições

Inicialmente é pertinente esclarecer que só recentemente os resíduos sólidos passaram a ser destaque como política pública nacional. Apesar disso, trata-se de um tema ainda pouco atrativo, haja visto a exiguidade de pesquisas que versam sobre o tema. Essa constatação é respaldada em Calderoni (2003, p. 25), quando afirma que "o lixo é um material mal-amado. Todos desejam dele descartar-se. Até pagam para dele se verem livres".

O termo lixo, segundo Gonçalves (2003, p. 19), deriva do latim lix, que significa: "lixívia ou cinza, numa época em que a maior parte dos resíduos de cozinha era formada por cinzas e restos de lenha carbonizada 
dos fornos e fogões; e, lixare (polir, desbastar); lixo seria então a sujeira, os restos, o supérfluo que a lixa arranca dos materiais".

Já para Calderoni (2003, p. 49) as definições de lixo e de resíduo são dinâmicas. Historicamente o lixo vem sendo interpretado com coisa imprestável. Brasil e Santos (2006, p. 292) argumentam:

A Organização Mundial de Saúde (OMS) define o lixo como qualquer coisa que seu proprietário não quer mais e que não possui valor comercial, sendo descartado pelo mesmo proprietário sem considerar que grande parte dos resíduos ainda possui valor comercial através da reutilização, reciclagem, ou sua reutilização como matéria-prima.

No entendimento de Waldman (2010, p. 18) "de um ponto de vista semântico, podemos certificar que lixo seria todo o material inútil, todo material descartado posto em algum lugar público, tudo aquilo que 'se joga fora', 'não presta', condição à qual são evocadas longas catilinárias devotadas à sua nocividade, periculosidade, intratabilidade etc".

Por sua vez, Pereira Neto (2007, p. 13), em contestação a essas formulações, diz que "torna-se, portanto, vidente, nos dias atuais, que essa definição de lixo está ultrapassada e não condiz mais com a urgente necessidade de proteção do meio ambiente e de controle do desperdício, principalmente por ir de encontro à visão moderna de gerenciamento do lixo". De acordo com Santos (2017, p. 93) "essa característica inservível do lixo deve ser considerada, no mínimo, relativa, pois aquilo que já não apresenta nenhuma serventia para quem o descarta, para outro pode se tornar matéria-prima para um novo produto ou processo".

Segundo Pereira Neto (2007, p. 13) "o lixo é uma massa heterogênea de resíduos sólidos resultantes das atividades humanas, que podem ser reciclados e parcialmente utilizados, gerando, entre outros benefícios, proteção à saúde pública e economia de energia e de recursos naturais". Entretanto, não é nosso propósito fazer distinção de tais conceitos. Mas, para efeito desta pesquisa adotaremos resíduos sólidos - termo empregado na Lei 12.305/2010, que institui a Política Nacional de Resíduos Sólidos (PNRS) - salientando que em alguns momentos iremos nos deparar com o termo lixo. Assim, os resíduos sólidos são definidos:

\begin{abstract}
Material, substância, objeto ou bem descartado resultante de atividades humanas em sociedade, a cuja destinação final se procede, se propõe proceder ou se está obrigado a proceder, nos estados sólidos, ou semissólido, bem como gases contidos em recipientes e líquidos cujas particularidades tornem viável o seu lançamento na rede pública de esgotos ou em corpos d'água, ou exijam para isso soluções técnica ou economicamente inviáveis em face da melhor tecnologia disponível (BRASIL, 2010, p. 2).
\end{abstract}

Cumpre ressaltar que a PNRS é esclarecedora nas definições desses termos. Para ela, rejeitos "são resíduos sólidos, que depois de esgotadas todas as possibilidades de tratamento e recuperação por processos tecnológicos disponíveis e economicamente viáveis, não apresentam outra possibilidade que não a disposição final ambientalmente adequada" (BRASIL, 2010, p. 2). Rejeito, portanto, é o mesmo que lixo. 


\section{A classificação dos resíduos sólidos}

A norma 10.004/1987/ABNT classifica os resíduos sólidos em: “Classe I ou perigosos, são aqueles que em função de suas propriedades podem apresentar riscos à saúde pública ou ao meio ambiente; Classe II, ou não inertes, são aqueles que não apresentam periculosidade; e Classe III, ou inertes, são aqueles que não se decompõem no solo". Para a ABNT, os resíduos sólidos são identificados a partir da sua origem e das características de periculosidade (MONTEIRO, 2017). Segundo Takayanagui (2005), a periculosidade de um resíduo está relacionada às suas propriedades físico-químicas e infecto-contagiosas pelo perigo à saúde, mortalidade e riscos ao ambiente pelo descarte irregular de resíduos.

Para a Fundação Nacional de Saúde - FUNASA (2006, p. 227) os resíduos sólidos são constituídos de substâncias:

Facilmente degradáveis (FD): restos de comida, sobras de cozinha, folhas, capim, cascas de frutas, animais mortos e excremento; Moderadamente degradáveis (MD): papel, papelão e outros produtos celulósicos; Dificilmente degradáveis (DD): trapo, couro, pano, madeira, borracha, cabelo, pena de galinha, osso, plástico; e Não degradáveis (ND): metal não ferroso, vidro, pedras, cinzas, terra, areia, cerâmica.

Por ter fortes origens nas atividades humanas, os resíduos sólidos apresentam diversas tipologias. Sobre estas, Barros et al. (1995, p. 185) enumeram uma série de classificações e origens para os mesmos (Doméstico, comercial, público, especial, hospitalar, industrial, construção civil ou entulho). Além destes, Grippi (2006, p. 25), acrescenta o lixo agrícola (resíduo oriundo das atividades agrícolas e da pecuária).

A falta de gerenciamento e de gestão integrada dos resíduos sólidos tem sido motivo de criação de propostas que busquem solucionar o problema, uma vez que as suas ausências ensejam impactos ao ambiente (poluição do solo, da água e do ar), conforme Quadro 1.

Quadro 1. Impactos ambientais provocados pelos lixões. Fonte: Adaptado do Rio Grande do Norte (2012).

\begin{tabular}{|l|l|}
\hline $\begin{array}{c}\text { Impactos ambientais nas } \\
\text { áreas de lixões }\end{array}$ & \multicolumn{1}{|c|}{ Consequências } \\
\hline Poluição do solo & $\begin{array}{l}\text { Os resíduos dispostos diretamente no solo sem qualquer tratamento poluem o solo com o } \\
\text { escoamento do chorume e alteram as propriedades naturais causando malefícios diretos } \\
\text { ou indiretos à vida humana, à natureza e ao meio ambiente em geral. }\end{array}$ \\
\hline $\begin{array}{l}\text { Poluição das águas } \\
\text { superficiais e subterrâneas }\end{array}$ & $\begin{array}{l}\text { A poluição das águas é causada pelo lançamento de dejetos industriais e agrícolas, esgoto } \\
\text { doméstico e resíduos sólidos. No caso dos lixões a céu aberto, onde o lixo é disposto } \\
\text { indiscriminadamente no solo é formado um líquido originado pela decomposição da } \\
\text { matéria orgânica, de fontes externas e das águas pluviais, chamado chorume ou percolado, } \\
\text { que contamina as águas superficiais de rios, lagos, podendo chegar às águas subterrâneas. }\end{array}$ \\
\hline
\end{tabular}




\begin{tabular}{|l|l|}
\hline $\begin{array}{c}\text { Impactos ambientais nas } \\
\text { áreas de lixões }\end{array}$ & \multicolumn{1}{|c|}{ Consequências } \\
\hline Poluição do ar & $\begin{array}{l}\text { A poluição do ar nas áreas de lixões tem origem na combustão espontânea do gás metano, } \\
\text { formado durante a decomposição anaeróbia dos resíduos orgânicos ou pela queima } \\
\text { intencional para reduzir o volume dos resíduos dispostos no local e prolongar a vida útil do } \\
\text { lixão. Entretanto, este gás liberado, acarreta malefícios diversos. }\end{array}$ \\
\hline Poluição visual & $\begin{array}{l}\text { A poluição visual em áreas de lixões torna-se impactante devido à alteração estética de um } \\
\text { determinado ambiente, pois a montanha de lixo contrasta de forma direta com a paisagem } \\
\text { natural, além de oferecer riscos. }\end{array}$ \\
\hline $\begin{array}{l}\text { Comprometimento a saúde } \\
\text { pública }\end{array}$ & $\begin{array}{l}\text { O lixo disposto sem nenhum tratamento ou cuidado técnico atrai diversos organismos } \\
\text { (macro e micro vetores) que são atraídos pela disponibilidade de água, alimento e abrigo. } \\
\text { Esses seres aliados ao poder contaminante do lixo podem transmitir doenças. }\end{array}$ \\
\hline
\end{tabular}

Independentemente de sua origem, os resíduos sólidos necessitam de tratamento final. A inexistência de tratamento adequado acarreta consequências. Na argumentação de Barros et al. (1995, p. 181), "dos pontos de vistas sanitário e ambiental, a adoção de soluções inadequadas para o problema do lixo faz com que seus efeitos indesejáveis se agravem: os riscos de contaminação do solo, do ar e da água". Igualmente, Pinheiro (2000, p. 60) alerta que o lixo quando não é disposto e tratado adequadamente, descartado em lixões, acaba por poluir o solo, o ar e a água. Pode, ainda, ser objeto para atração de vetores (insetos e roedores), risco de fogo, de deslizamentos, de explosões, de espalhamento pelo vento, das presenças de animais, de pessoas e do tempo de decomposição dos materiais (SILVA FILHO, 2006, p. 49-50).

De fato, os resíduos sólidos têm se apresentado como um dos mais graves problemas no mundo atual, com fortes ameaças ao homem e ao Planeta. A disposição dos resíduos em lixões a céu aberto, por representar uma das práticas mais comuns na maioria das cidades brasileiras, se constitui como potencial causador de impactos ao meio-ambiente ${ }^{1}$. Corroborando essa discussão, Motta (2006, p. 138) assegura que "a gestão de resíduos sólidos no Brasil apresenta indicadores que mostram um baixo desempenho dos serviços de coleta e, principalmente, na disposição final do lixo urbano. Este fraco desempenho gera problemas sanitários e de contaminação hídrica nos locais onde são depositados esses resíduos".

\footnotetext{
${ }^{1} \mathrm{O}$ conceito de impacto ambiental é correlato aos conceitos de degradação ambiental e de poluição e vem ao encontro na Resolução CONAMA 01/86 nos seguintes termos: considera-se impacto ambiental qualquer alteração das propriedades físicas, químicas e biológicas do meio ambiente, causada por qualquer forma de matéria ou energia resultante das atividades humanas que, direta ou indiretamente, afetam: a saúde, a segurança e o bem-estar da população; as atividades sociais e econômicas; a biota. As condições estéticas e sanitárias do meio ambiente e a qualidade dos recursos ambientais (DIAS, 2009, p. 151).
} 


\section{A disposição dos resíduos sólidos no Brasil, Rio Grande do Norte e no Vale do Açu}

A falta de gestão e de gerenciamento dos resíduos sólidos na maioria dos municípios do país tem desnudado um problema perceptível a todos, desde muito tempo, que é a incapacidade do poder público e da coletividade em tratar adequadamente os resíduos sólidos.

Descrevendo sobre o gerenciamento do lixo urbano, Grippi (2006, p. 21), diz:

Gerenciar lixo na concepção da palavra significa cuidar dele do berço ao túmulo; esta expressão 'do berço ao túmulo' define muito bem como deve ser o gerenciamento do lixo nos dias de hoje: desde sua geração, a seleção e finalmente sua disposição final.

A constatação do mau gerenciamento dos resíduos sólidos pode ser notada nos dados da Associação Brasileira de Empresa de Limpeza Pública e Resíduos Especiais - ABRELPE (2015) que revelam que 58,4\% dos municípios encaminham seus resíduos gerados e coletados para locais impróprios; ou seja, dos 5.570 municípios existentes, 3.331 destinam os resíduos sólidos urbanos (RSUs) para locais não adequados ambientalmente.

Esta realidade pode ser constatada nos dados do "Panorama dos Resíduos Sólidos no Brasil 2015", por ela realizado. Nele é possível notar que dos 5.570 municípios, 2.244 dispõem os seus resíduos em aterros sanitários, 1.774 encaminham para aterros controlados e 1.552 descartam em lixões a céu aberto. Ou seja, 3.326 municípios não tratam adequadamente os resíduos gerados.

No tocante ao Rio Grande do Norte (RN) a situação dos resíduos sólidos é muito mais crítica do que os dados gerais da região Nordeste. Historicamente, os estados dessa região têm apresentado resultados insatisfatórios no tocante ao tratamento final dos RSUs. Além de não existir aterros sanitários suficientes e programas de coleta seletiva de materiais recicláveis, na maioria das cidades é possível constatar ruas sujas e lixões a céu aberto.

Com base nos dados da Tabela 1 é possível observar que das 3.049 toneladas/dia de resíduos sólidos geradas em 2015, apenas 2.695 toneladas/dia foram coletadas e tiveram destino final conhecido. Além da elevada quantidade de resíduos sólidos destinados para aterros controlados e lixões, o mais grave é que 354 toneladas não foram coletas e sequer se sabe o seu destino. O mais provável é que esses resíduos foram descartados em espaços das cidades, criando outros pequenos lixões.

Tabela 1. Geração e coleta de resíduos sólidos, em toneladas no Rio Grande do Norte. Fonte: ABRELPE (2015).

\begin{tabular}{ccccccccc}
\hline \multirow{2}{*}{$\begin{array}{c}\text { População Total do Rio Grande } \\
\text { do Norte }\end{array}$} & \multicolumn{2}{c}{$\begin{array}{c}\text { RSU Gerado } \\
\text { (t/dia) }\end{array}$} & \multicolumn{3}{c}{ Kg/hab/dia) } & \multicolumn{3}{c}{ t/dia) } \\
\cline { 5 - 9 } 2014 & 2015 & 2014 & 2015 & 2014 & 2015 & 2014 & 2015 \\
3.408 .510 & 3.442 .175 & 3.009 & 3.049 & $\mathbf{0 , 7 8 0}$ & $\mathbf{0 , 7 8 3}$ & $\mathbf{2 . 6 5 7}$ & $\mathbf{2 . 6 9 5}$ \\
\hline
\end{tabular}


Do total de 3.049 toneladas/dia de resíduos sólidos urbanos (RSU) geradas no RN, em 2015, 2.695 $(88,3 \%)$ toneladas tiveram destinos finais para aterro sanitário (760), aterro controlado (1.017) e lixão (918). No geral, 1.935 toneladas tiveram como destino os lixões a céu aberto e os aterros controlados, diariamente. Apenas 760 toneladas foram destinadas adequadamente para aterros sanitários (Tabela 2).

Tabela 2. População, produção total, per capita em kg e situação das áreas de disposição final dos resíduos sólidos coletados nos municípios da microrregião do Vale do Açu (2014). Fonte: Silva Filho (2019, p. 242), adaptado do Rio Grande do Norte (2016c, 2016e).

\begin{tabular}{|c|c|c|c|c|}
\hline Municípios & $\begin{array}{l}\text { População } \\
\text { estimada }\end{array}$ & $\begin{array}{l}\text { Produção de } \\
\text { resíduos sólidos } \\
\text { (toneladas/ano) }\end{array}$ & $\begin{array}{l}\text { Produção per capita de } \\
\text { resíduos sólidos } \\
\text { (kg/hab./dia) }\end{array}$ & $\begin{array}{c}\text { Situação das áreas de } \\
\text { disposição final dos resíduos } \\
\text { sólidos (lixões) }\end{array}$ \\
\hline Alto do Rodrigues & 13.915 & 2.876 & 0,55 & $\begin{array}{c}\text { Notificado a realizar } \\
\text { adequações }\end{array}$ \\
\hline Assú & 57.292 & 2.334 & 0,96 & Autuado \\
\hline Carnaubais & 10.760 & 3.157 & 0,81 & Vistoriado \\
\hline Ipanguaçu & 15.147 & 4.328 & 0,79 & Apresentou nova área \\
\hline Itajá & 7.457 & 1.555 & 0,58 & Vistoriado \\
\hline Jucurutu* & - & - & - & - \\
\hline Pendências & 14.751 & 3.875 & 0,73 & $\begin{array}{c}\text { Notificado a realizar } \\
\text { adequações }\end{array}$ \\
\hline Porto do Mangue & 5.884 & 1.454 & 0,69 & Autuado \\
\hline São Rafael & 8.347 & 1.752 & 0,57 & $\begin{array}{c}\text { Notificado a realizar } \\
\text { adequações }\end{array}$ \\
\hline Total & 133.553 & 21.331 & 0,71 & - \\
\hline
\end{tabular}

Nos municípios da microrregião do Vale do Açu, por exemplo, essa realidade é visível a olho nu. Em muitas das cidades dessa microrregião os lixões que compõem o cartão postal paisagístico, em sua totalidade, são ocultados pelos gestores e pelas populações.

Vale ressaltar que nessa região os resíduos gerados pela população urbana são, em sua totalidade, dispostos em vazadouros a céu aberto, assim como ocorre nos demais 15 (quinze) municípios que optaram por integrar o Consórcio Regional de Saneamento Básico do Vale do Açu. Na microrregião do Vale do Açu essa situação é preocupante, já que a totalidade dos resíduos sólidos gerados diariamente pela população é disposta em lixões, em áreas próximas dos centros urbanos, de reservatórios hídricos e junto à vegetação nativa de caatinga (Figura 2). 
Figura 2. Áreas de disposição final de resíduos sólidos na área de abrangência da Região de Assú e municípios do Vale do Açu. Fonte: Silva Filho (2019, p. 226), adaptado do Rio Grande do Norte (2016d, p. 20).

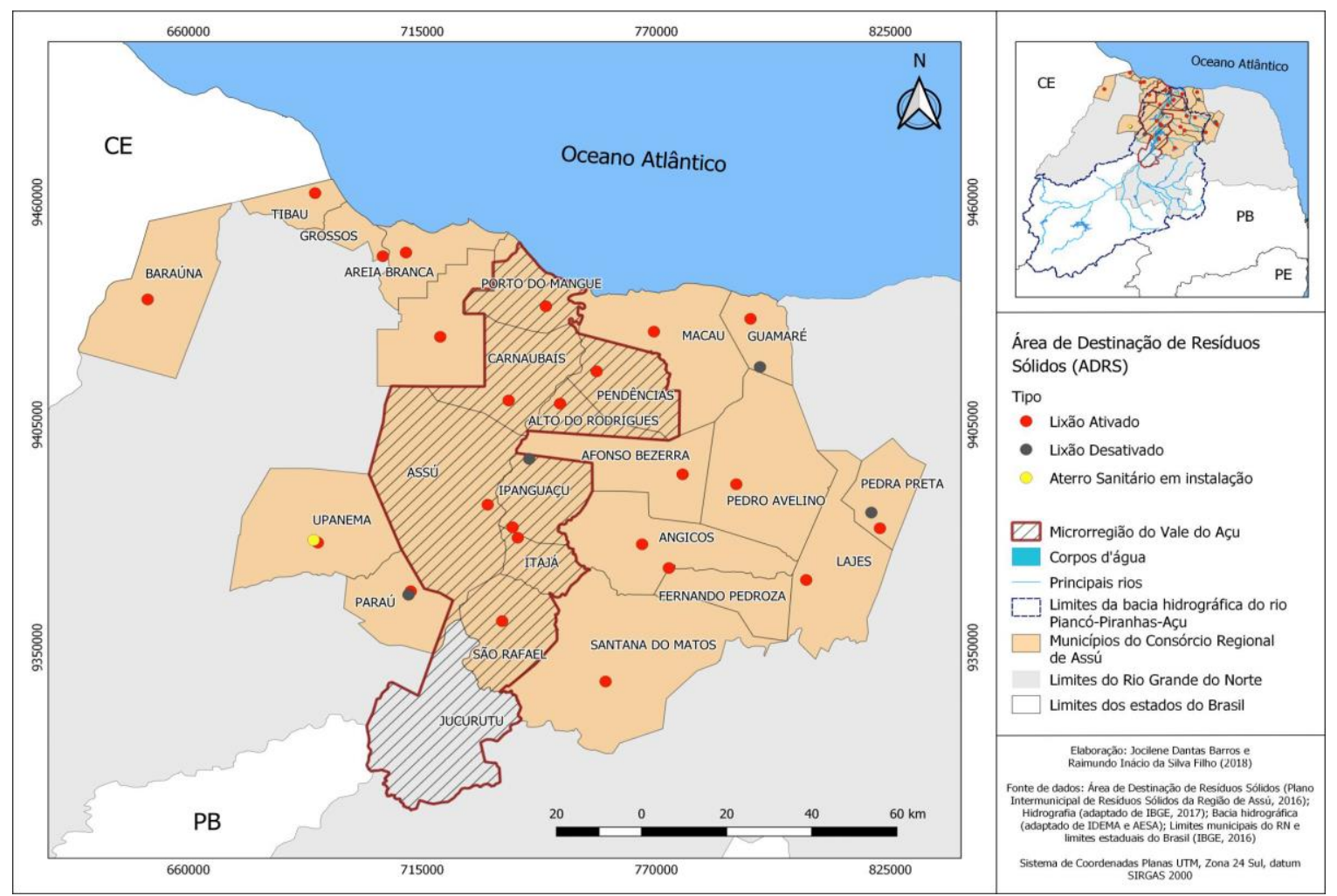

Em todos os municípios do Consórcio Regional de Saneamento Básico do Vale do Açu a disposição final dos resíduos sólidos ocorre próxima aos núcleos urbanos e corpos hídricos, em alguns municípios a distância é de poucos metros, conforme mostra a Tabela 3.

Tabela 3. Distâncias das áreas de destinação final dos resíduos sólidos em relação ao núcleo urbano e aos corpos d'água na Região de Assú. Fonte: Silva Filho (2019, p. 227), adaptado do Rio Grande do Norte (2016b).

\begin{tabular}{|c|c|c|c|c|}
\hline \multirow{2}{*}{ ITEM } & \multirow{2}{*}{ MUNICÍPIOS } & \multicolumn{3}{|c|}{ Distâncias consideradas (km) } \\
\hline & & ADRS* & Dos núcleos urbanos & Dos corpos hídricos \\
\hline 01 & Afonso Bezerra & Lixão & 2 & 0,5 \\
\hline 02 & Alto do Rodrigues** & Lixão & 5 & 1,5 \\
\hline $03 *$ & Angicos & Lixão & 1 & 2 \\
\hline 04 & Areia Branca & Lixão & 3,5 & 1 \\
\hline 05* & Assú** & Lixão & 0 & 0,2 \\
\hline 06 & Baraúna & Lixão & 3,8 & $>5$ \\
\hline 07 & Carnaubais** & Lixão & 3 & 2,5 \\
\hline 08 & Fernando Pedroza & Lixão & 0,7 & 0,5 \\
\hline 09 & Grossos & Lixão & 2 & 0,03 \\
\hline 10 & Guamaré & Lixão & 13 & 1 \\
\hline $11^{*}$ & Ipanguaçu** & Lixão & 6 & 1,8 \\
\hline 12 & Itajá** & Lixão & 3 & 1,2 \\
\hline
\end{tabular}




\begin{tabular}{|c|c|c|c|c|}
\hline \multirow{2}{*}{ ITEM } & \multirow{2}{*}{ MUNICÍPIOS } & \multicolumn{3}{|c|}{ Distâncias consideradas (km) } \\
\hline & & ADRS* & Dos núcleos urbanos & Dos corpos hídricos \\
\hline 13 & Lajes & Lixão & 3 & 1,6 \\
\hline 14 & Macau & Lixão & 10 & 1,2 \\
\hline 15 & Paraú & Lixão & 1 & 0,6 \\
\hline 16 & Pedra Preta & Lixão & 4 & 0,8 \\
\hline 17 & Pedro Avelino & Lixão & 1,5 & 0,3 \\
\hline 18 & Pendências** & Lixão & 2 & 1,4 \\
\hline 19 & Porto do Mangue** & Lixão & 8 & 0,4 \\
\hline 20 & Santana do Matos & Lixão & 2 & 0,6 \\
\hline 21 & São Rafael** & Lixão & 1,5 & 0,2 \\
\hline 22 & Serra do Mel & Lixão & 2 & $>5$ \\
\hline 23 & Tibau & Lixão & 6,5 & 1 \\
\hline 24 & Upanema & Lixão & 3,1 & 4 \\
\hline
\end{tabular}

Com efeito, analisando a situação do distanciamento das Áreas de Disposição de Resíduos Sólidos (ADRS) na Região de Assú, Rio Grande do Norte (2016b) mostra:

Muitos municípios da Região possuem Áreas de Disposição de Resíduos Sólidos (ADRS) implantadas nas proximidades de corpos d'água (barreiros, açudes, pequenos riachos ou rios), algumas chegando a apenas $30 \mathrm{~m}$ de distância, o que pode comprometer a qualidade desses recursos. Neste sentido, a maior distância registrada é de $4 \mathrm{~km}$ da ADRS em relação ao corpo d'água, no município de Upanema.

De fato, além de o tratamento inadequado dos resíduos sólidos se constituir um dos sérios problemas no meio ambiente regional, a situação dos mesmos se torna ainda mais crítica pela forma como são dispostos nas localidades próximas dos corpos hídricos. Essa prática, que já ameaça contaminar as águas da região, é comumente despercebida.

Por todas as questões acima elencadas, Schneider et al (2013, p. 14) admitem ser "natural que as soluções para a destinação final dos resíduos sólidos urbanos sejam intermunicipais". Não se admite deixar que este problema, que se espraia e ultrapassa limites territoriais das cidades e dos estados federados, permaneça apenas sob a responsabilidade individual do gestor municipal (prefeito).

Assim sendo, elencamos a formação dos consórcios públicos no Brasil. Isso porque é consenso entre os especialistas de que a lei que trata dos consórcios públicos no Brasil é indispensável, principalmente para os municípios de baixo poder econômico e que pretende seguir as orientações da PNRS, como forma de erradicação dos lixões e destinar adequadamente os resíduos sólidos para os aterros sanitários. Alguns especialistas, a exemplo de Baldissera (2015); Cunha (2004); Farias Filho (2007); Oliveira (2004); Piterman (2014); Ribeiro (2007); Rikils (2015); Rio Grande do Norte (2012); Schneider et al. (2013) e Silva (2015) reconhecem a Lei 11.107/2005 como sendo o "marco legal” dos consórcios públicos no Brasil. 


\title{
Os consórcios públicos intermunicipais no Brasil
}

Os primeiros registros de regulação geral de consórcio público no país já estavam presentes desde o regime constitucional brasileiro de 1891 (NASCIMENTO NETO; MOREIRA, 2012; RIBEIRO, 2007). Entretanto, a ideia de cooperação institucional não surtiu o efeito desejado, muito embora o Assunto estivesse, respectivamente, presente nos textos constitucionais de 1937 e 1967 (OLIVEIRA, 2004). É bem verdade que naquela época a autonomia dos municípios era bastante reduzida, em função do forte centralismo da União nos períodos do "Estado Novo" (1937-1946) e da "Ditadura Militar" (1964-1985).

Embora não sendo ainda incentivado pelo governo federal, Oliveira (2004) mostra que os primeiros registros de consórcios intermunicipais no Brasil ocorreram em 1956, em três municípios do Estado de Pernambuco (Vivência, Bom Jardim e João Alfredo), em 1960 nos Estados do Rio Grande do Sul (Associação dos Municípios do Vale do Rio dos Sinos - AMVRS) e de São Paulo (Bauru). Uma das razões apontada por não haver crescimento dos consórcios no país é que significou "um período de centralização do poder, quando a União decidia tudo, como forma de controle totalitário" (OLIVEIRA, 2004, p. 40). Corroborando o autor acima Silva (2015, p. 62) aponta:

\begin{abstract}
A ideia de consorciamento não é recente no Brasil, datando do século XIX as primeiras possibilidades de união de diferentes entes municipais para a cooperação e/ou resolução de uma determinada questão que necessitasse de parcerias, lembrando que a organização político-administrativa do Brasil não era no sentido federativo, ou seja, a centralização nas decisões era muito evidente.
\end{abstract}

Entretanto, vale ressaltar que mesmo sem o apoio federal o crescimento dos consórcios públicos revela ser questão de tempo. Nesse período alguns Estados incentivavam a criação de associações civis com o intuito de buscar soluções para alguns problemas comuns e pertinentes a vários municípios. Ainda, segundo Cunha (2004, p. 13), "com o crescimento da atuação dos municípios em diferentes áreas de políticas públicas, em especial por volta da década de 1970, antes mesmo do novo desenho federativo formalizado pela Constituição de 1988, os mecanismos de consorciamento expandem-se e ganham visibilidade".

No final da década 1990, com a promulgação da Constituição Federal de 1988, os municípios e o Distrito Federal são impulsionados a formar consórcios, pelo fato de os mesmos serem reconhecidos como entes federativos, numa perspectiva de repartição mais distributiva dos recursos financeiros e de "autonomia". A partir de então, embora num processo ainda lento, porém com um pouco mais de segurança, os consórcios públicos ressurgem no Brasil. Em 1998, o Art. 241 da Constituição Federal de 1988 (CF) recebeu a Emenda Constitucional no 19 de 1998 (EC), dando nova versão para o instituto do consórcio público.

De fato, a EC 19/98 passa a ser um passo fundamental para a consolidação do instituto dos Consórcios públicos no país, oferecendo maior garantia jurídica e administrativa às parcerias realizadas entre os 
consorciados (FARIAS FILHO, 2007, p. 36). A partir da Constituição Federal (CF) de 1988 é impulsionada a criação de consórcios públicos no país, principalmente na área de saúde. Desse modo, "a Constituição de 1988 consolidou novo processo de redemocratização e, mais uma vez, o sistema federativo foi restaurado" (RIBEIRO, 2007, p. 16).

Sete anos após a incorporação da EC 19/98 e ao Art. 241 da CF de 1988, emergem amplas discussões no âmbito da Câmara dos Deputados e do Senado Federal que culminará com a aprovação a Lei 11.107, de 5 de abril de 2005 - Lei dos Consórcios Públicos (LCP) - que dispõe, no Art. 1o, "sobre normas gerais para a União, os Estados, o Distrito Federal e os Municípios contratarem consórcios públicos para a realização de objetivos de interesse comum", regulamentada pelo Decreto 6.017, de 17 de janeiro de 2007.

De posse dessa segurança jurídica institucional a criação de consórcios públicos no país se fortalece. Este mecanismo despertou e difundiu nos gestores públicos municipais a necessidade e importância dos consórcios públicos. Dados do Perfil dos Municípios Brasileiros, extraídos da Pesquisa de Informações Básicas Municipais 2015, (IBGE, 2016, p. 37) revela um crescimento de 23,01\% na modalidade horizontal (consórcios entre os municípios) do consórcio, saindo de 2.903, em 2011, para 3.571, em 2015.

A partir do exposto, percebe-se que diante do problema dos resíduos sólidos no Brasil, nas mais diversas regiões e municípios, o instituto do consórcio público se constitui como imprescindível para a gestão e o gerenciamento ambientalmente adequado dos resíduos. Para isso Lopes (2007) aponta que a adoção de um modelo compartilhado por meio do consórcio intermunicipal auxiliará os municípios no enfrentamento dos resíduos sólidos, principalmente na sua destinação final. Ainda assim, Nascimento Neto e Moreira (2012, p. 267), alertam que apesar dos consórcios públicos emergirem de uma alternativa de gestão do território em um fim específico, o seu processo de criação e de funcionamento não está isento de impasses e desafios. Embora haja consenso entre diversos especialistas sobre a importância dos consórcios públicos para solucionar o problema dos resíduos sólidos nos municípios, principalmente entre aqueles com baixo poder econômico, os mesmos também relatam preocupações que inviabilizam a sua implantação.

Destarte, os especialistas no assunto argumentam que os consórcios públicos, considerado como instrumento fundamental para a gestão dos resíduos sólidos nos municípios brasileiros, não têm conseguido avançar a ponto de superar os obstáculos existentes (BRASIL, 2017; BALDISSERA, 2015; MARTINS, AGUIAR; ASSUNÇÃO, 2015; NASCIMENTO NETO; MOREIRA, 2012; ROLNIK, 2012; SILVA, 2015; VARGAS, 2012; FONSECA, 2010; SUZUKI; GOMES, 2009; FARIAS FILHO, 2007; OLIVEIRA, 2004).

No entendimento de Silva (2015, p. 124), dentre os problemas que dificultam a implementação do consórcio público, o principal aspecto dificultador 'é a mudança das gestões municipais, ou questões partidárias que podem vir a interferir no processo de consolidação do consórcio'. Além desta, a distância da 
sede do aterro sanitário, as condições das rodovias e o não envolvimento da população são tidos como entraves no êxito dos consórcios.

Para Farias Filho (2007) a preocupação dos prefeitos que já vivenciaram a experiência do consórcio público recaí sobre a sustentabilidade financeira do empreendimento, a ausência de gestão profissional, a falta de técnicos especializados, os erros de concepção de projeto, os desentendimentos entre diversos atores e instituições, a indefinição quanto aos critérios de cobranças junto aos consortes e o distanciamento do Estado. Segundo ele, na fase inicial do projeto é indispensável apoio estadual em diferentes áreas financeiras, administrativas e técnicas.

Já para Suzuki e Gomes (2009) o "fator político-partidário" e a distância superior a 50 km da sede operacional do aterro sanitário são fatores que se apresentam como barreira para o êxito do consórcio intermunicipal. Para Fonseca (2010, p. 105) "a ausência do Poder Público e do Estado na articulação nos municípios de pequeno e médio porte constitui-se no principal entrave para os avanços na implantação dos consórcios públicos municipais, independente da área de atuação".

Por sua vez, Nascimento Neto e Moreira (2012, p. 267) destacam a ausência de participação popular, a ausência de identidade regional (falta de consciência metropolitana) e a assimetria de forças (desequilíbrios de poderes econômicos e institucionais dos municípios, influenciando nas negociações entre os mesmos). Segundo eles, isso decorre de condicionantes históricos e institucionais.

\section{Principais resultados}

Apesar da existência e orientações da PNRS, o Consórcio de Saneamento Básico do Vale do Açu ainda não conseguiu se efetivar na prática, por diversos motivos: a distância da sede do município ao aterro sanitário, o fator político-partidário, a crise financeira dos municípios, o número elevado de municípios na composição do Consórcio e a ausência de envolvimento da população se constituem como entraves ao seu êxito.

O fator distância entre as cidades consorciadas e a sede operacional (município onde se localiza o aterro sanitário) é considerado relevante por especialistas uma vez que influenciam na logística e no custo de transporte.

Analisando a distância entre as sedes dos municípios da Região de Assú, temos que dos vinte e quatro integrantes do Consórcio Regional de Saneamento Básico do Vale do Açu, apenas três apresentam distâncias inferiores a 30 km: Assú (14,8), Ipanguaçu (16) e Itajá (22,6); seis se localizam em distâncias de até 50 km: Itajá $(22,6)$, Angicos $(33,7)$, São Rafael $(39,5)$, Paraú $(42,5)$, Carnaubais $(47,4)$ e Alto do Rodrigues $(49,4)$; quinze 
apresentam distâncias superiores a 50 km: Pendências (51,3), Afonso Bezerra (62,3), Porto do Mangue $(65,0)$, Serra do Mel $(66,6)$, Upanema $(68,7)$, Macau $(78,8)$, Lajes $(82,0)$, Areia Branca $(85,6)$, Santana do Matos $(89,1)$, Pedro Avelino (95,4), Guamaré $(98,7)$, Baraúna (111), Tibau (113), Pedra Preta $(113,4)$ e Grossos.

A distância média da sede do aterro sanitário (Assú) entre os demais municípios que compõem o Consórcio de Saneamento Básico do Vale do Açu é de $70 \mathrm{~km}$. Assim, a partir dos estudos de Suzuki e Gomes (2009), os quais consideram a distância máxima de 50 km entre as sedes municipais como a distância a ideal, é possível afirmar essa variável como um fator que dificulta a implantação do Consórcio.

O fator político-partidário também se percebe como variável que tem comprometido a implantação do Consórcio. Depois da sua criação, e da adesão dos prefeitos em 2010, já ocorreram eleições municipais duas eleições: 2012 e 2016, respectivamente. Em todos os municípios que integram o Consórcio de Saneamento Básico do Vale do Açu foram eleitos novos prefeitos, configurando o estabelecimento de novas geografias político-partidárias. $\mathrm{O}$ atual quadro político-partidário dos municípios que integram o Consórcio é composto por nove legendas político-partidárias, a saber: PR (5), PMDB (4), PSD (6) DEM (2), PSDB (3), SD (1), PP (1), PHS (1) e PRB (1).

A falta de recursos financeiros e a discordância com o atual formato geográfico do atual Consórcio são questões centrais também consideradas pelos prefeitos e ex-prefeitos, no tocante aos desafios para a implantação do referido consórcio público. Por fim, em consonância com essas questões, tem-se, sobretudo, o distanciamento da sociedade civil na discussão sobre o destino dos seus resíduos sólidos como um dos motivos preponderantes para o malogro do Consórcio de Saneamento Básico do Vale do Açu.

\section{CONSIDERAÇÕES FINAIS}

O projeto de pesquisa que concebeu esta investigação teve como objetivo principal desvendar os limites e obstáculos que entravam a operacionalização do Consórcio Regional de Saneamento Básico do Vale do Açu, referente à gestão e ao gerenciamento dos resíduos sólidos, segundo a opinião dos gestores (ex-prefeitos, prefeitos em exercício e secretários) dos municípios que integram geograficamente a microrregião do Vale do Açu e dos representantes da FEMURN, da SEMARH e do próprio Consórcio.

Inicialmente, é pertinente destacar que os gestores municipais (prefeitos) reconhecem a necessidade de implantação do consórcio público e que os municípios isoladamente não têm condições financeiras suficientes para tratar adequadamente os resíduos sólidos e que isso só será possível mediante aporte financeiro dos governos estadual e federal. Todavia, as questões político-partidárias, as distâncias entre as 
cidades, a localização do aterro sanitário e a ausência de práticas de gestão compartilhada são obstáculos existentes, mas que podem ser superadas a partir do aporte financeiro às prefeituras.

Entretanto, diante dessas constatações, asseguramos que os motivos que limitam a operacionalização deste Consórcio restam além dos mencionados. Embora conhecidamente destacados, a superação desses obstáculos carece de outras ações. Por exemplo, não notamos sintonia entre a Política Nacional de Resíduos Sólidos - PNRS e a Política Nacional de Recursos Hídricos - PNRH, uma vez que na microrregião do Vale do Açu estão localizados os maiores reservatórios hídricos do Rio Grande do Norte. Igualmente, não se detecta nenhuma articulação efetiva entre o Ministério do Meio Ambiente - MMA, o Ministério das Cidades MCidades, a Agência Nacional de Águas - ANA e a Fundação Nacional de Saúde - FUNASA no diálogo desse tema com os municípios. Tampouco se verifica ações das secretarias municipais e estadual de Educação na discussão dessa importante temática com a população.

Diante do exposto, concluímos que apesar da regionalização dos consórcios de resíduos sólidos no RN já ter dado um passo adiante, ela ainda está muito distante das recomendações da PNRS, já que as causas centrais que dificultam a sua operacionalização não foram analisadas. Associado a essas questões, tem-se, sobretudo, o distanciamento da sociedade civil na discussão dos resíduos sólidos, apesar de que esta já convive com esse problema, desde muito tempo.

De fato, a política de regionalização é bem aceitável pelos prefeitos, contudo, por si só ela não é suficiente para mitigar o problema pela simples proposta de agrupamentos de municípios, uma vez que o RN já é reincidente na prática de regionalização das atividades econômicas, do turismo e da saúde, sem que tivessem ocorrido avanços substantivos nessas áreas.

Por fim, reconhecemos que por mais promissores que sejam a PNRS, as propostas de consórcios intermunicipais de resíduos sólidos dificilmente terão êxito sem o envolvimento dos entes governamentais e da população. Não notamos segurança no Estado brasileiro em querer assumir essa responsabilidade. Igualmente, não se constata a existência de "solidariedade institucional" e clareza de competências nos órgãos governamentais (MMA, MCidades e FUNASA) para tratar a PNRS junto aos municípios.

\section{REFERÊNCIAS}

AGÊNCIA EUROPEIA DE MEIO AMBIENTE. Los residuos: ¿un problema o un recurso? Copenhague: EEA, 2014. 11p. Disponível em: <https://www.eea.europa.eu/downloads/ab42a3726d7b43b0bcc143af4ab3efb2/1472651944/los-residuos-un-problema-o.pdf>. Acesso em: 11 fev. 2018.

ASSOCIAÇÃO BRASILEIRA DAS EMPRESAS DE LIMPEZA PÚBLICA E RESÍDUOS ESPECIAIS - ABRELPE. Panorama dos resíduos sólidos no Brasil 2015. 2015. Disponível em: <http://www.abrelpe.org.br/Panorama/panorama2015.pdf>. Acesso em: 28 set. 2017. 
BALDISSERA, Darlan Sampietro. Consórcios públicos intermunicipais no Brasil: panorama após 10 anos de Lei 11.107/2005. 2015. 65f. Dissertação (Mestrado em Administração Pública) - Escola Brasileira de Administração Pública e de Empresas, Centro de Formação Acadêmica e de Pesquisa da Fundação Getúlio Vargas, Rio de Janeiro, 2015.

BAUMAN, Zygmunt. Vida para consumo: a transformação das pessoas em mercadoria. 2. ed. Rio de Janeiro: Zahar, 2008. 200p.

BAUMAN, Zygmunt. Vida liquida. 2. ed. Rio de Janeiro: Zahar, 2009. 210p.

BARROS, Rafhael Tobias de Vasconcelos et al. (Ed.). Manual de saneamento e proteção ambiental para os municípios. Belo Horizonte: DESA; UFMG, 1995. 221p.

BRASIL. Decreto 6.017, de 17 de janeiro de 2007. Regulamenta a Lei no 11.107, de 6 de abril de 2005, que dispõe sobre normas gerais de contratação de consórcios públicos. Diário Oficial da União, 18 jan. 2007b. Disponível em: <http://www.planalto.gov.br/ccivil_03/_ato2007-2010/2007/decreto/d6017.htm>. Acesso em: 3 nov. 2017.

BRASIL. Lei 12.305, de 2 de agosto de 2010. Institui a Política Nacional de Resíduos Sólidos; altera a Lei no 9.6055, de 12 de fevereiro de 1998. Diário Oficial da União, 3 ago. 2010. Disponível em: <http://www.planalto.gov.br/ccivil_03/_ato2007-

2010/2010/lei/l12305.htm>. Acesso em: 2 de out. 2017.

BRASIL. Constituição (1988): atualizada até a EC 96/98. Brasília: Supremo Tribunal Federal, 2018. Secretaria de Documentação. 514p. Disponível em: <http://www.stf.jus.br/arquivo/cms/legislacaoConstituicao/anexo/CF.pdf>. Acesso em: 3 nov. 2017.

BRASIL. Relatório de avaliação por área de gestão no 9: resíduos sólidos. Ministério da Transparência e Controladoria-Geral da União. Secretaria Federal de Controle Interno. Brasília, 2017. 76p. Disponível em: <https://auditoria.cgu.gov.br/download/9805.pdf>. Acesso em: 10 de fev. 2019.

BRASIL, Anna Maria; SANTOS, Fátima. O ser humano e o meio ambiente de A a Z: dicionário. 2. ed. São Paulo: FAARTE, 2006.

CALDERONI, Sabetai. Os bilhões perdidos no lixo. São Paulo: Humanitas, 2003. 346p.

CAPRA, Fritjof. O ponto de mutação. São Paulo: Cultrix, 2002. 445p.

COMPROMISSO EMPRESARIAL PARA RECICLAGEM - CEMPRE. Lixo municipal: manual de gerenciamento integrado. 4. ed. São Paulo: CEMPRE, 2018a. 316p.

COMPROMISSO EMPRESARIAL PARA RECICLAGEM - CEMPRE. Pesquisa ciclosoft 2018. 2018b. Disponível em: <http://cempre.org.br/ciclosoft/id/9>. Acesso em: 9 fev. 2019.

COMPROMISSO EMPRESARIAL PARA RECICLAGEM - CEMPRE. Cempre-review 2019. São Paulo: CEMPRE, 2019. 37p. Disponível em: <http://cempre.org.br/upload/CEMPRE-Review2019.pdf>. Acesso em: 20 dez. 2018.

CUNHA, Rosani Evangelista da. Federalismo e relações intergovernamentais: os consórcios públicos como instrumento de cooperação federativa. Revista do Serviço Público. Revista do Serviço Público, Brasília, v. 55, n. 3, p. 1, jul./set. 2004. Disponível em: <https://revista.enap.gov.br/index.php/RSP/article/view/249>. Acesso em: 28 fev. 2018.

DIAS, Gilka da Mata. Cidade sustentável: fundamentos legais, política urbana, meio ambiente e saneamento básico. Natal: Editora do autor, 2009.

EIGENHEER, Emílio Maciel (Org.). Coleta seletiva de lixo. Rio de Janeiro: Universidade Federal Fluminense - UFF; Centro de Informação Sobre Resíduos Sólidos - CIRS, 1998. (Experiências Brasileiras, 2). 208p.

FARIAS FILHO, Waldecy Ferreira. Consórcios intermunicipais para gestão de resíduos sólidos urbanos: análise da implementação do Portal Mata Sul. 2007. 73f. Dissertação (Mestrado em Geografia) - Programa de Pós-Graduação em Geografia, Universidade Federal de Pernambuco, Recife, 2007.

FONSECA, Devanilda Ranieri Martins da. O consórcio público intermunicipal como instrumento de gestão dos resíduos sólidos urbanos: um estudo de caso nos municípios de Tucuruí e Breu Branco (Estado do Pará). 2010. 137f. Dissertação (Mestrado em Gestão dos Recursos Naturais e Desenvolvimento Local na Amazônia) - Núcleo de Meio Ambiente, Programa de Pós-Graduação em Gestão dos Recursos Naturais e Desenvolvimento Local, Universidade federal do Pará, Belém, 2010.

FUNASA - Fundação Nacional de Saúde. Manual de saneamento: engenharia de saúde pública (orientações técnicas) 3 ed. Brasília: Assessoria de comunicação e educação em saúde. 2006. 408p.

GONÇALVES, Pólita. A reciclagem integradora dos aspectos ambientais, sociais e econômicos. Rio de Janeiro: DP\&A, 2003. 182p.

GRIPPI, Sidney. Lixo: reciclagem e sua história - guia para as prefeituras brasileiras. 2. ed. Rio de Janeiro: Interciência, 2006. 166p. 
INSTITUTO BRASILEIRO DE GEOGRAFIA E ESTATÍSTICA - IBGE. Perfil dos municípios brasileiros 2015: pesquisa de informações básicas municipais. Coordenação de População e Indicadores Sociais. Rio de Janeiro: IBGE, 2016. 61p.

KAUTSKY, Karl. A questão agrária. Brasília: Instituto Teotônio Vilela, 1998. 588p.

LOPES, José Carlos de Jesus. Resíduos sólidos urbanos: consensos, conflitos e desafios na gestão institucional da Região Metropolitana de Curitiba. 2007. 250f. Tese (Doutorado em Meio Ambiente e Desenvolvimento) - Universidade Federal do Paraná, Curitiba, 2007.

MANDELLI, Suzana Maria de Conto; LIMA, Luiz Mário; OJIMA, Mário K. (Org.). Tratamento de resíduos sólidos: compêndio de publicações. Caxias do Sul: UCS, 1991. 291p.

MARTINS, L. F.; AGUIAR, V. F. S.; ASSUNÇÃO, S. G. S. Desafios dos consórcios públicos intermunicipais na gestão dos resíduos sólidos no Brasil: estudo de caso nos consórcios públicos Vale do Santa Tereza - CONVALE e Vale do Serra Dourada - VALECON. In: INTERNATIONAL WORKSHOP - ADVANCES IN CLEANOR PRODUCION - Cleaner Production Towards a Sustainable Transition, 5, 2015, São Paulo. Anais... São Paulo, 2015. 10p.

MONTEIRO, Alessandra da Rocha Duailibe. Poluição por resíduos. In: SANTOS, Marco Aurélio dos (Org.). Poluição do meio ambiente. Rio de Janeiro: LTC, 2017. p. 93-126.

MOTTA, Ronaldo Seroa da. Economia ambiental. Rio de Janeiro: FGV, 2006. 228p.

NASCIMENTO NETO, Paulo; MOREIRA, Tomás Antonio. Consórcio intermunicipal como instrumento de gestão de resíduos sólidos urbanos em regiões metropolitanas: reflexões teórico-conceituais. Revista Brasileira de Gestão e Desenvolvimento Regional, Taubaté, SP, v. 8, n. 3, p. 239-282, set./dez. 2012.

NUNES, Ana Cristina Tavares; BASTOS, Valéria Pereira. Políticas públicas de sustentabilidade urbana no gerenciamento de resíduos sólidos. O social em questão: Revista do Departamento de Serviço Social da PUC - Rio, Rio de Janeiro, ano 21, n. 40, p. 253-266, jan./abr. 2018. Disponível em: <http://osocialemquestao.ser.puc-rio.br/cgi/cgilua.exe/sys/start.htm?infoid=588\&sid=55>. Acesso em: 25 fev. 2018.

OLIVEIRA, Gilberto de. Consórcio intermunicipal para o manejo integrado de lixo em cinco municípios da região administrativa de Bauru. 2004. 129f. Dissertação (Mestrado em Geografia) - Instituto de Geociências e Ciências Exatas), Universidade Estadual Paulista, Campus Rio Claro, Rio Claro, SP, 2004.

PEREIRA NETO, João Tinôco. Gerenciamento do lixo urbano: aspectos técnicos e operacionais. Viçosa, MG: Editora FGV, 2007. 129p.

PHILIPPI JÚNIOR, Arlindo (Ed.). Saneamento, saúde e ambiente: fundamentos para um desenvolvimento sustentável. Barueri, SP: Manole, 2005. 842p. (Coleção Ambiental, 2).

PINHEIRO, Sérgio Bezerra. Os resíduos sólidos urbanos na cidade de Natal e a avaliação ambiental da remediação do lixão de Cidade Nova. 2000. 199f. Dissertação. (Mestrado em Recursos Hídricos e Saneamento Ambiental) - Centro de Tecnologia, Universidade Federal do Rio Grande do Norte, Natal, 2000.

PITERMAN, Ana. Formação e implantação dos consórcios intermunicipais em saneamento: um estudo de três experiências no Brasil. 2014. 274f. Tese (Doutorado em Saneamento, Meio Ambiente e Recursos Hídricos) - Escola de Engenharia, Programa de PósGraduação em Saneamento, Meio Ambiente e Recursos Hídricos, Universidade Federal de Minas Gerais, Belo Horizonte, 2014.

RIBEIRO, Wladimir António. Cooperação federativa e a lei de consórcios públicos. Brasília/DF: Confederação Nacional dos Municípios - CNM, 2007. 72p.

RILKILS, Vanuscleia Silva Santos. Estudo de viabilidade de um consórcio público intermunicipal de resíduos sólidos urbanos na região sul do estado de Roraima, RR, Brasil. 2015. 170f. Dissertação (Mestrado em Ambiente e Desenvolvimento) - Programa de PósGraduação Stricto Sensu, Centro Universitário Univates, Lajeado, 2015.

RIO GRANDE DO NORTE. Protocolo de intenções de consórcio público regional de saneamento básico do Vale do Açu. Natal: SEMARH, 2010b. 78p. Impresso.

RIO GRANDE DO NORTE. Plano estadual de gestão integrada de resíduos sólidos do Rio Grande do Norte - PEGIRS/RN: Relatório síntese. Natal, RN: SEMARH, 2012. 158p.

RIO GRANDE DO NORTE. Plano intermunicipal de resíduos sólidos da Região do Açu. Natal, RN: Brencorp; Consultoria em Meio Ambiente Ltda, 2016a.

RIO GRANDE DO NORTE. Plano intermunicipal de resíduos sólidos da região do Assú. Produto 2 - Elaboração do diagnóstico regional dos resíduos sólidos da região do Assú. Natal, RN: SEMARH, 2016b. 246p. 
RIO GRANDE DO NORTE. Plano intermunicipal de resíduos sólidos da região do Assú do Estado do Rio Grande do Norte (PIRS/Assú/RN). Produto 1.2 - Oficinas para validação do diagnóstico regional de resíduos sólidos e do estudo do arranjo intermunicipal. Natal, RN: SEMARH, 2016c. 70p.

RIO GRANDE DO NORTE. Plano intermunicipal de resíduos sólidos da região do Assú do Estado do Rio Grande do Norte (PIRS/Assú/RN). Produto 3 - Estudo da gestão associada. Natal, RN: SEMARH, 2016d. 188p.

RIO GRANDE DO NORTE. Plano intermunicipal de resíduos sólidos da região do Assú do Estado do Rio Grande do Norte (PIRS/Assú/RN). Produto 1 - Elaboração do diagnóstico dos resíduos sólidos dos municípios da região do Assú. Anexo 1 - Estudo da caracterização física dos resíduos sólidos (Gravimetria). Natal, RN: SEMARH, 2016e. 125p.

RIO GRANDE DO NORTE. Plano intermunicipal de resíduos sólidos da região de Assú - PIRS/Assú. Produto 4 - Planejamento das ações do PIRS. Natal, RN: SEMARH, 2016f. 162p.

ROLNIK, Raquel. Resíduos sólidos urbanos: repensando suas dimensões. In: SANTOS, Maria Cecília Loschiavo dos; GONÇALVES-DIAS, Sylmara Lopes Francelino. Resíduos sólidos urbanos e seus impactos ambientais. São Paulo: IEE-USP, 2012. p. 18-22.

SANTOS, Marco Aurélio dos (Org.). Poluição do meio ambiente. Rio de Janeiro: LTC, 2017. 146p.

SCHNEIDER, Moche Dan; RIBEIRO, Wladimir Antonio; SALOMONI, Daniel. Orientações básicas para a gestão consorciada de resíduos sólidos. Fundação Instituto para o Fortalecimento das Capacidades Institucionais - IFC/Agência Espanhola de Cooperação Internacional para o Desenvolvimento - AECID/Ministério do Planejamento, Orçamento e Gestão - MPOG. Brasília: IABS, 2013. 220p.

SILVA, Wagner Luiz Alves da. Consórcio público regional de resíduos sólidos urbanos do Seridó/RN: perspectivas de um novo modelo de gestão. 2015. 152f. Dissertação (Mestrado em Estudos Urbanos Regionais) - Programa de Pós-Graduação em Estudos Urbanos Regionais, Universidade Federal do Rio Grande do Norte, Natal, RN, 2015.

SILVA FILHO, Raimundo Inácio da. O lixo em Natal: o potencial sócio-econômico e a nova dinâmica sócio-territorial. Natal: Departamento Estadual de Imprensa, 2006. 161p.

SILVA FILHO, Raimundo Inácio da. A gestão dos resíduos sólidos na microrregião do Vale do Açu: desafios e perspectivas do consórcio regional de saneamento básico. 2019. 206f. Tese (Doutorado em Geografia, Programa de Pós-Graduação em Geografia, Recife, 2019. Disponível em:

<https://repositorio.ufpe.br/bitstream/123456789/34411/1/TESE\%20Raimundo\%20In\%C3\%A1cio\%20da\%20Silva\%20Filho.pdf>. Acesso em: 21 mar. 2020.

SINDICATO DAS EMPRESAS DE LIMPESA URBANA NO ESTADO DE SÃO PAULO - SELUR. Índice de sustentabilidade da limpeza urbana para os municípios brasileiros. 2. ed. São Paulo: PwC/SELUR, 2017. 114p. Disponível em:

<https://www.selur.com.br/publicacoes/islu-indice-de-sustentabilidade-da-limpeza-urbana-para-os-municipios-brasileiros-2aedicao-2017/>. Acesso em: 16 jul. 2018.

SUZUKI, Juliana Akiko Noguchi; GOMES, João. Consórcios intermunicipais para a destinação de RSU em aterros regionais: estudo prospectivo para os municípios no Estado do Paraná. Revista Engenharia Sanitária Ambiental, Rio de Janeiro, v. 14, n. 2, abr./jun. 2009. Disponível em: <http://www.scielo.br/scielo.php?script=sci_arttext\&pid=S1413-41522009000200002>. Acesso em: 22 mar. 2018.

VARGAS, Guilherme Pereira de. Os consórcios públicos no planejamento e gestão regionalizada do território brasileiro: as experiências mineiras do COM10 e CODAP. 2012. 176f. Dissertação de Mestrado (Instituto de Geociências, Departamento de Geografia) - Universidade Federal de Minas Gerais, Belo Horizonte, 2012.

TAKAYANAGUI, Angela Maria Magosso. Gerenciamento de resíduos de serviços de saúde. In: PHILIPPI JÚNIOR, Arlindo (Ed.). Saneamento, saúde e ambiente: fundamentos para um desenvolvimento sustentável. Barueri, SP: Manole, 2005. p. 323-374. (Coleção Ambiental, 2). 842p.

WALDMAN, Maurício. Lixo: comentários e desafios - abordagens básicas para entender os resíduos sólidos. São Paulo: Cortez, 2010. $232 p$. 